\title{
Effects of encoding and retrieval contexts on recall
}

\author{
SLATER E. NEWMAN and MARY ANN OLSEN \\ North Carolina State University, Raleigh, North Carolina 27650 \\ and \\ ANTHONY D. HALL and ROSEMARY HORNAK \\ Meredith College, Raleigh, North Carolina 27611
}

\begin{abstract}
On a single study trial, each target word was accompanied by a cue word to which it was preexperimentally weakly or strongly associated. On the test, subjects were presented with a different set of words (retrieval cues), to which the target words were also preexperimentally weakly or strongly associated, or with no retrieval cues at all and were asked to recall as many of the encoding cue words as possible. Recall was better for those given no retrieval cues than for those who received either the strong or weak cues at retrieval. However, neither the strength of the encoding cues nor of the retrieval cues affected the amount recalled.
\end{abstract}

In a recent extralist cuing experiment (Newman, Cooper, Parker, Sidden, Gonder-Frederick, Moorefield, \& Nelson, 1982, Experiment 8), subjects were given a list of target words to study, each of which was accompanied by a cue word to which it was either weakly or strongly preexperimentally associated. They were instructed to associate each target word with its cue word $^{1}$ and were later tested for recall of the target words with a different set of preexperimentally weakly or strongly related retrieval cue words or with no cue words at all. This experiment, which employed a 2 by 2 between-subjects design, was used to test both the encoding specificity hypothesis (Thomson \& Tulving, 1970), which holds that only those cues present at encoding will be effective retrieval cues, and the semantic integration hypothesis (Baker \& Santa, 1977; Santa, Note 1), which provides that the flexibility of retrieval of a target word is inversely related to the degree to which it is integrated with its cue word. The prediction derivable from the encoding specificity hypothesis is that there will be no differences in recall among the six treatments, based on the assumption that none of the cues present at encoding was present at retrieval. ${ }^{2}$ The semantic integration hypothesis, however, predicts an inverse relationship between the number of target words recalled and the strength of the relationship between the encoding cue and its target word. Contrary to both predictions, recall was found to be directly related both to the strength of the relationships

Completion of this paper was facilitated by an honorary research fellowship granted to the senior author by the Department of Psychology, Birkbeck College, University of London, which he much appreciates. Requests for reprints should be sent to Slater E. Newman, Department of Psychology, North Carolina State University, Raleigh, North Carolina 27650.
(1) between the target word and its cue word and (2) between the target word and its retrieval cue. Similar findings have been reported by Hunt (1975).

One explanation for these results is that (1) during retrieval subjects attempt to recall the target words through generating the encoding cues, $(2)$ for both cued and uncued recall it is easier to generate the strong than the weak encoding cues, and (3) strong (as compared with weak) extralist cues facilitate recall of the encoding cues. The present experiment was designed to evaluate Assumptions 2 and 3 through testing for recall of the encoding cues.

\section{METHOD}

\section{Procedure}

The materials and procedure were those used in the experiment by Newman et al. (1982, Experiment 8), except that on the test, subjects were asked to recall the encoding cues rather than the target words. In the present experiment, subjects studied a list of 16 target words, each of which was accompanied by an encoding cue word. For half of the subjects, the encoding cues were preexperimentally weakly associated $(1 \%)$ with the target words; for the remaining subjects, the encoding cues were more strongly associated $(31 \%)$ with the target words. The weak and strong cues were selected to be unrelated to each other in the norms. On the study trials, each pair of words was presented for 2 sec, the subjects having been previously instructed to remember the target word by associating it with its cue word.

For the test, subjects from each encoding condition were assigned to one of three retrieval cue conditions: (1) strongly associated (31\%) extralist retrieval cues, (2) weakly associated (1\%) extralist retrieval cues, or (3) no retireval cues. Subjects in the extralist retrieval cue conditions were instructed to write down as many of the encoding cue words as they could recall using the "new" cue words to help them remember. Subjects in the no retrieval cue condition were given a blank sheet of paper on which they were instructed to write as many of the encoding cues as they could remember. All subjects were tested individually and were given $2 \mathrm{~min}$ for the test. A stopwatch was 
Table 1

Mean Items Recalled, Mean Latency (in Seconds), and Number of Subjects for Each Treatment

\begin{tabular}{|c|c|c|c|c|c|c|c|c|c|}
\hline \multirow{3}{*}{$\begin{array}{c}\text { Encoding } \\
\text { Condition }\end{array}$} & \multicolumn{9}{|c|}{ Retrieval Condition } \\
\hline & \multicolumn{3}{|c|}{ Strong Cue } & \multicolumn{3}{|c|}{ Weak Cue } & \multicolumn{3}{|c|}{ No Cue } \\
\hline & Recall & Latency & $\mathrm{N}$ & Recall & Latency & $\mathrm{N}$ & Recall & Latency & $\mathrm{N}$ \\
\hline $\begin{array}{l}\text { Strong Cue } \\
\text { Weak Cue }\end{array}$ & $\begin{array}{l}3.92 \\
2.58\end{array}$ & $\begin{array}{l}14.34 \\
14.25\end{array}$ & $\begin{array}{l}12 \\
24\end{array}$ & $\begin{array}{l}2.12 \\
2.83\end{array}$ & $\begin{array}{l}22.82 \\
24.64\end{array}$ & $\begin{array}{l}24 \\
12\end{array}$ & $\begin{array}{l}4.92 \\
4.33\end{array}$ & $\begin{array}{l}3.07 \\
3.41\end{array}$ & $\begin{array}{l}12 \\
12\end{array}$ \\
\hline
\end{tabular}

used to record the latency of each subject's first response on the test.

\section{Subjects and Design}

The subjects were 96 undergraduates at North Carolina State University. A 2 by 3 between-subjects design was used, in which the independent variables were encoding context (weak or strong cues) and retrieval context (weak or strong extralist cues or no cues). The number of subjects assigned to each treatment appears in Table 1.

\section{RESULTS}

The mean number of different encoding cues recalled by subjects in each condition is presented in Table 1 . (For all of the statistical tests reported here, the probability of a Type I error was set at .05.) An analysis of variance applied to these data showed that only the effect of retrieval context was significant $[F(2,90)=$ 7.94, MSe $=4.01$ ]. Subsequent Duncan's tests (with Kramer's correction for unequal cell sizes) indicated that the mean for the group that had no retrieval cues exceeded the means for the two groups that had extralist cues at retrieval, but that the latter two means did not differ from each other.

The mean latency (in seconds) for each of the six conditions also appears in Table 1. Analysis of variance for these data also gave a significant effect for retrieval context $[\mathrm{F}(2,90)=11.42, \mathrm{MSe}=252.62]$. Application of Duncan's test (again with Kramer's correction) to means for the three retrieval cue conditions showed that the no-cue mean exceeded both the strong-cue and weak-cue means and that the strong-cue mean was also higher than the mean for the weak-cue group.

\section{DISCUSSION}

In the experiment reported by Newman et al. (1982, Experiment 8), recall was found to be directly related to the strength of the relationship between the target and both its encoding cue and its extralist retrieval cue. To explain these results, it was proposed that (1) during retrieval the subject attempts to recall the target word by generating its encoding cue, (2) it is easier to generate strong than weak encoding cues in both cued and uncued recall, and (3) recall of encoding cues is directly related to the strength of extralist retrieval cues.

The present experiment was done to evaluate Assumptions 2 and 3 , the predictions being that for both cued and uncued recall, the number of encoding cues recalled will be directly related to the strength of the relationship between the target word and its encoding cue and that for cued recall only, the number of encoding cues recalled will be directly related to the strength of the relationship between the target word and its extralist retrieval cue. Although the strong-cue mean exceeded the weak-cue mean both for the encoding context and for the retrieval context, neither difference was significant. Thus these data do not support the explanation reported above for the Newman et al. (1982) results. Rather, their results appear to be better handled by an associative continuity position that emphasizes the effects of transsituational stability in the strength of the cue-target relationship (Bahrick, 1969, 1970). Thus, the stronger the relationship between cue and its target, the more effective it will be as a retrieval cue, independent of whether it was present only at encoding or at retrieval.

Subjects for whom no cues were present at retrieval recalled more encoding cues than subjects for whom either weak or strong extralist cues were present. They also had much shorter latencies for their first responses. Thus, when extralist retrieval cues were present, subjects may have first examined the list of retrieval cues before attempting to recall the encoding cues. This would have the effect of increasing the length of the retention interval for subjects in the extralist cue conditions, who might thus be expected to recall fewer encoding cues than if extralist cues had not been present at retrieval.

This explanation leads also to the expectation that the shorter latency when strong (as compared with weak) cues were present at retrieval will be accompanied by better recall of encoding cues, but this did not happen. Perhaps the use in future studies of paced rather than unpaced retrieval will allow for more effective experimenter control of the length of the retention interval and thus help reduce this as a possible source of confounding.

\section{REFERENCE NOTES}

1. Santa, J. L. Integration and cued recall. Paper presented at Symposium on Cue-Dependent Forgetting, American Psychological Association, Toronto, September 1978.

2. Tulving, E. Personal communication, November 1976.

\section{REFERENCES}

Bahrick, H. P. Measurement of memory by prompted recall. Journal of Experimental Psychology, 1969, 79, 213-219.

Bahrick, H. P. A two-phase model for prompted recall. Psychological Review, 1970, 77, 215-222.

BAKer, L., \& SAnta, J. L. Context, integration, and retrieval. Memory \& Cognition, 1977, 5, 308-314.

HuNT, R. R. How similar are context effects in recognition and recall? Journal of Experimental Psychology: Human Learning and Memory, 1975, 1, 530-537.

Newman, S. E., Cooper, M. H., Parker, K. O., Sidden, J. A., Gonder-Frederick, L. A. Moorefield, K. M., \& Nelson, P. A. Some tests of the encoding specificity and semantic integration hypotheses. American Journal of Psychology, 1982, 95, 103-123.

Thomson, D. M., \& Tulving, E. Associative encoding and retrieval: Weak and strong cues. Journal of Experimental Psychology, 1970, 86, 255-262. 
Tulving, E. Relation between encoding specificity and levels of processing. In L. S. Cermak \& F. I. M. Craik (Eds.), Levels of processing in human memory. Hillsdale, N.J: Erlbaum, 1979.

\section{NOTES}

1. According to Tulving (Note 2), this procedure is functionally equivalent to that of using one or more set-establishing lists (Thomson \& Tulving, 1970, Experiment 2) to foster cuetarget relationships.
2. Tulving (1979) has emphasized the distinction between the encoding specificity hypothesis, which is testable, and the encoding specificity principle, which is not. It sometimes turns out that an increase in recall accompanies the presentation at retrieval of a cue that was not presented at encoding. This result, although not in accord with the encoding specificity hypothesis, is handled by the encoding specificity principle, an assumption being that the cue was present at encoding, even though it was not overtly presented.

(Received for publication November 15, 1982.) 